\title{
Adjuvant Radiotherapy and/or Chemotherapy for Endometrial Cancer, Status as at 2019
}

\author{
Opinion of the Uterus Commission of the Gynecological Oncology \\ Working Group (AGO)
}

\section{Adjuvante Strahlen- und/oder Chemotherapie des Endometriumkarzinoms, Stand 2019}

\author{
Stellungnahme der Kommission Uterus der Arbeitsgemeinschaft \\ Gynäkologische Onkologie (AGO)
}

(두)(i) (오 $\ominus$

\author{
Authors \\ for the Uterus Commission of the AGO
}

Günter Emons ${ }^{1}$, Clemens Tempfer ${ }^{2}$, Marco Johannes Battista ${ }^{3}$, Alexander Mustea ${ }^{4}$, Dirk Vordermark ${ }^{5}$,

Correspondence

Prof. Günter Emons

UMG, Frauenklinik

emons@med.uni-goettingen.de
Robert-Koch-Straße 40, 37075 Göttingen, Germany

$\Theta$

Deutsche Version unter:

https://doi.org/10.1055/a-1019-7720

\section{ABSTRACT}

The role of adjuvant radiotherapy and/or chemotherapy in the primary treatment of endometrial cancer with a high risk of recurrence has still not been conclusively determined. The results of 3 large randomized controlled studies on different aspects of this issue have been published in full in recent months, and the relevant results are analyzed here.

Bibliography

DOI https://doi.org/10.1055/a-1019-7720

Geburtsh Frauenheilk 2019; 79: 1273-1277 @ Georg Thieme Verlag KG Stuttgart · New York | ISSN 0016-5751

\section{ZUSAMMENFASSUNG}

Die Rollen von adjuvanter Radio- und/oder Chemotherapie in der Primärbehandlung des Endometriumkarzinoms mit hohem Rezidivrisiko sind nicht eindeutig geklärt. In den letzten Monaten wurden Vollpublikationen von 3 großen randomisierten kontrollierten Studien zu verschiedenen Aspekten dieser Problematik vorgelegt, die im Kontext analysiert werden.
The first full publication of the international Post-Operative-Radiation-Therapy-in-Endometrial-Cancer (PORTEC)-3 trial one year ago attracted considerable attention. Adjuvant simultaneous radiochemotherapy followed by adjuvant chemotherapy ( $\triangleright$ Table 1) did not lead to a significant improvement in the overall survival of women with high-risk endometrial cancer compared to radiotherapy alone [1]. However, the data were still immature [1]. Additional chemotherapy only achieved an improvement in failurefree survival after 5 years. The side effects of the additional chemotherapy were substantial [1]. 
- Table 1 Recent, randomized, controlled studies on adjuvant therapy for endometrial cancer.

\begin{tabular}{|c|c|c|c|c|c|}
\hline & Patients & Treatment & Toxicity & Recurrence & Overall survival \\
\hline $\begin{array}{l}\text { PORTEC-3 } \\
{[1,5]}\end{array}$ & $\begin{array}{l}\text { Endometrioid EC: } \\
\text { stage IA, G3 + LVSI; } \\
\text { stage IB, G3; } \\
\text { stage II-IIIC; } \\
\text { Serous or clear cell EC } \\
\text { stage I-III } \\
\mathrm{n}=660\end{array}$ & $\begin{array}{l}\text { Percutaneous } 48.5 \text { Gy } \\
\pm \text { brachytherapy } \\
+2 \times \text { cisplatin } 50 \mathrm{mg} / \mathrm{m}^{2} \\
\text { followed by } 4 \times \text { carbo- } \\
\text { platin AUC } 5+\text { paclitaxel } \\
175 \mathrm{mg} / \mathrm{m}^{2} \text { versus radio- } \\
\text { therapy alone (percuta- } \\
\text { neous } \pm \text { brachytherapy) }\end{array}$ & $\begin{array}{l}\text { Acute: } 60 \text { vs. } 12 \% \text { neu- } \\
\text { ropathies } \\
\text { ( } \geq \text { grade } 2 \text { ) } \\
\text { After } 5 \text { years: } 6 \text { vs. } 0 \%\end{array}$ & $\begin{array}{l}\text { Failure-free survival after } \\
5 \text { years: } 76.5 \text { vs. } 69.1 \% \\
\text { (adjusted HR: } 0.70 ; \\
\mathrm{p}=0.016 \text { ) } \\
\text { More significant effect in } \\
\text { stage III and for serous EC }\end{array}$ & $\begin{array}{l}\text { 5-year OS: } 81.4 \text { vs. } \\
76.1 \% \text { (adjusted HR: } \\
0.7 ; p=0.034 \text { ) } \\
\text { More significant } \\
\text { effect in stage III } \\
\text { and on serous EC }\end{array}$ \\
\hline $\begin{array}{l}\text { GOG-258 } \\
{[6]}\end{array}$ & $\begin{array}{l}\text { Stage III and IV a EC } \\
\text { (all histological } \\
\text { types), residual } \\
\text { tumor }<2 \mathrm{~cm} \text { or } \\
\text { serous/clear cell EC } \\
\text { Stage - II with } \\
\text { positive cytology } \\
\mathrm{n}=736\end{array}$ & $\begin{array}{l}\text { Percutaneous pelvic } \\
\text { irradiation } \pm \text { paraaortic } \\
\text { field } \pm \text { brachytherapy } \\
+2 \times \text { cisplatin } 50 \mathrm{mg} / \mathrm{m}^{2} \\
\text { followed by } 4 \times \text { carbo- } \\
\text { platin AUC } 6+\text { paclitaxel } \\
175 \mathrm{mg} / \mathrm{m}^{2} \mathrm{vs} .6 \times \text { car- } \\
\text { boplatin AUC } 6+\text { pacli- } \\
\text { taxel } 175 \mathrm{mg} / \mathrm{m}^{2}\end{array}$ & $\begin{array}{l}\text { Side effects } \geq \text { grade } 3 \\
\text { in } 58 \% \text { (chemo/radio- } \\
\text { therapy) vs. } 63 \% \\
\text { (chemotherapy alone) }\end{array}$ & $\begin{array}{l}\text { Recurrence-free } 5 \text { - year } \\
\text { survival: } 59 \text { vs. } 58 \% \text { (HR: } \\
0.90 ; 90 \% \mathrm{Cl}=0.74- \\
1.10) \\
\text { Fewer vaginal and pelvic/ } \\
\text { paraaortic recurrences } \\
\text { but more distant metas- } \\
\text { tases in the chemo/ } \\
\text { radiotherapy group }\end{array}$ & Data too immature \\
\hline $\begin{array}{l}\text { GOG-249 } \\
{[7]}\end{array}$ & $\begin{array}{l}\text { FIGO I-II: } \\
\text { endometrioid EC with } \\
\text { "high-intermediate } \\
\text { risk" or } \\
\text { serous or clear cell } \\
\text { EC with negative } \\
\text { cytology } \\
n=601\end{array}$ & $\begin{array}{l}\text { Vaginal brachytherapy } \\
+3 \times \text { carboplatin AUC } 6+ \\
\text { paclitaxel } 175 \mathrm{mg} / \mathrm{m}^{2} \text { vs. } \\
\text { percutaneous irradiation } \\
\text { (45-51 Gy) } \pm \text { vaginal } \\
\text { brachytherapy }\end{array}$ & $\begin{array}{l}\text { Acute toxicity higher } \\
\text { in the brachytherapy/ } \\
\text { chemotherapy arm } \\
\text { Late toxicity the same } \\
\text { for both groups }\end{array}$ & $\begin{array}{l}\text { Recurrence-free 5-year } \\
\text { survival: } \\
76 \text { vs. } 76 \% \text {; vaginal and } \\
\text { distant metastasis the } \\
\text { same; pelvic and para- } \\
\text { aortic lymph node recur- } \\
\text { rence somewhat more } \\
\text { common in the brachy- } \\
\text { therapy/chemotherapy } \\
\text { group ( } 9 \text { vs. } 4 \% \text { ) }\end{array}$ & $\begin{array}{l}\text { 5-year OS: } 85 \% \\
\text { (brachytherapy + } \\
\text { chemotherapy) vs. } \\
87 \% \text { (percutaneous } \\
\text { radiotherapy) }\end{array}$ \\
\hline
\end{tabular}

PORTEC: Postoperative Radiation Therapy in Endometrial Cancer; EC: endometrial cancer; AUC: area under the curve; OS: overall survival; GOG: Gynecologic Oncology Group

The German Society for Radio-Oncology (DEGRO) concluded that radiotherapy alone would remain the treatment of choice in this setting. A combination of chemotherapy and radiotherapy should only be considered for patients with high-risk stage III tumors or serous cell carcinoma [2].

The Uterus Commission of the AGO interpreted the results of the PORTEC-3 trial slightly more cautiously than DEGRO did and did not see any need to amend the current S3-guideline "Diagnosis, Therapy and Follow-up of Patients with Endometrial Cancer" [3] as long as no mature survival data from the PORTEC-3 trial were available [4]. According to the current S3-guideline, the basis of adjuvant therapy to treat patients with lymph node involvement, involvement of the uterine serosa, the adnexa, the vagina, bladder or rectum (stage III - IV a disease) is chemotherapy. Postoperative pelvic irradiation may be carried out in addition to improve local control $[3,4]$.

A post-hoc survival analysis of the PORTEC-3 trial has now been published, which shows that after a median follow-up time of 72.6 months, additional chemotherapy led to a significant improvement in overall survival [5].

The American GOG-258 trial, which considered chemotherapy alone to be the standard for patients with stage III and IVa EC, reported in the first full publication of its results that additional ra- diotherapy did not lead to any improvement in recurrence-free survival [6].

The first full publication of the results of the GOG-249 trial, which compared adjuvant radiotherapy \pm brachytherapy with brachytherapy plus 3 cycles of carboplatin/paclitaxel to treat high/intermediate risk EC stage I and II, is now available [7].

Based on all of these new data [5-7], it is now possible to issue more reliable recommendations than one year ago.

\section{Current Status of the PORTEC-3 Trial}

This trial investigated patients $(n=660)$ with high-risk EC ( $\triangleright$ Table 1). Approximately $45 \%$ of patients had stage III disease, $26 \%$ had stage IIIC, i.e., had lymph node metastasis. $25 \%$ of patients had serous or clear cell (type 2) EC, $32 \%$ had poorly differentiated (G3) endometrioid EC [5]. When looking at the total patient population, the most recent analysis (median follow-up: 72.6 months) reported a 5 -year overall survival rate of $81.4 \%(95 \% \mathrm{Cl}=77.2-$ $85.8)$ for the group which received chemo- and radiotherapy vs. $76.1 \%(71.6-80.9)$ for the group which received radiotherapy alone (HR: $0.7 ; 95 \% \mathrm{Cl}=0.51-0.97 ; \mathrm{p}=0.034)$. The 5-year failure-free survival rate was $76.5 \%(95 \% \mathrm{Cl}=71.5-80.7)$ vs. $69.1 \%$ (63.8-73.8; HR: 0.7; 95\% Cl=0.52-0.94; $\mathrm{p}=0.01$ ). In most pa- 
tients, distant metastasis was the first manifestation of recurrence. Distant metastasis occurred in $21.4 \%$ of women in the chemo/radiotherapy group and in $29.1 \%$ of women in the group which received radiotherapy alone [5]. A subgroup analysis of patients with stage I and II EC found no significant differences in overall survival and failure-free survival for patients who additionally received chemotherapy. However, in the subgroup of patients with stage III EC or serous EC, the addition of chemotherapy resulted in a significant improvement in the 5-year overall survival rate: 78.5 vs. $68.5 \%$ (stage III; $p=0.043$ ) and 71.4 vs. $52.8 \%$ (serous $E C ; p=0.037$ ) as well as in the failure-free survival rate: 70.9 vs. $58.4 \%$ (stage III; $\mathrm{p}=0.011$ ) and 59.7 vs. $47 \%$ (serous $\mathrm{EC}$; $\mathrm{p}=0.008)$ [5].

The most recent analysis found that after 5 years the side effects were similar in both groups. Only sensory neuropathies were more common in the chemo/radiotherapy arm [5]. The authors concluded that combined chemo/radiotherapy, consisting of pelvic irradiation with 2 simultaneous administrations of cisplatin, followed by 4 cycles of carboplatin/paclitaxel should be recommended to patients with serous and/or stage III EC [5]. This includes all patients with pelvic and/or paraaortic lymph node metastasis, irrespective of the local spread of the primary tumor.

\section{Current Status of the GOG-258 Trial}

Based on the results of its earlier randomized trials, the American Gynecologic Oncology Group considers systemic chemotherapy to be the most useful adjuvant therapy to treat high-risk EC in patients with resected locally advanced EC [6]. In contrast to adjuvant radiotherapy, chemotherapy was able to improve survival in earlier studies [6]. However, the administration of chemotherapy alone was associated with a high rate of locoregional recurrence. The aim of the GOG-258 trial was therefore to determine whether standard therapy (6 cycles of adjuvant chemotherapy with carboplatin/paclitaxel) could be improved by combining it with external radiotherapy based on the extent of tumor spread (adjuvant radiochemotherapy with cisplatin, followed by 4 cycles of adjuvant chemotherapy with carboplatin/paclitaxel) [6].

A total of 736 patients with high-risk EC ( $\vee$ Table 1$)$, of whom $>97 \%$ had stage III disease, 50\% had stage IIIC1, 25\% had stage IIIC2 and $21 \%$ had serous or clear cell EC, received adjuvant treatment after surgery consisting either of chemotherapy alone or a combination of chemo/radiotherapy in analogy to treatment in the PORTEC-3 trial. If paraaortic lymph node involvement (IIIC2) was also present, this region was also irradiated [6]. The median follow-up time was 47 months. The recurrence-free 5 -year survival rate was $59 \%(95 \% \mathrm{Cl}=53-64 \%)$ in the chemo/radiotherapy group and $58 \%(53-64 \%)$ in the group treated with chemotherapy alone (HR: $0.9 ; 90 \% \mathrm{Cl}=0.74-1.10)$. In accordance with the study hypothesis, additional radiotherapy resulted both in fewer vaginal recurrences (2 vs. $7 \%$; $\mathrm{HR}: 0.36 ; 95 \% \mathrm{Cl}=0.16-0.82$ ) and fewer pelvic and paraaortic lymph node recurrences ( 11 vs. $20 \%$; HR: $0.43 ; 95 \% \mathrm{Cl}=0.28-0.66)$. However, distant metastasis was more common in the group with chemo/radiotherapy compared to the group which received only chemotherapy ( 27 vs. $21 \%$; HR: $1.36 ; 95 \% \mathrm{Cl}=1.00-1.86$ ). Side effects $\geq$ grade 3 were reported for $58 \%$ of patients in the chemo/radiotherapy group and $63 \%$ of patients who had chemotherapy alone. The addition of radiotherapy to chemotherapy did not improve recurrence-free survival. It remains to be seen in the remaining follow-up time whether the reduction in the frequency of distant metastasis in the group with chemotherapy alone will have an impact on overall survival [6].

\section{Current Status of the GOG-249 Trial}

This trial aimed to investigate whether for high/intermediate risk and high-risk patients with stage I and II EC, adjuvant vaginal brachytherapy followed by shortened chemotherapy (3 cycles) would be more effective than percutaneous radiotherapy \pm brachytherapy ( $\triangleright$ Table 1) [7]. High/intermediate risk was defined as age $\geq 70$ years plus 1 uterine risk factor, age $\geq 50$ years plus 2 risk factors or age $\geq 18$ years plus 3 risk factors. Uterine risk factors were G2 and G3 tumors, pT1b and lymphatic vessel invasion [7]. Pelvic and paraaortic lymphadenectomy was recommended and carried out in $90 \%$ of patients. Alternatively, CT or MRI was done postoperatively to exclude enlarged lymph nodes. $21 \%$ of patients had endometrioid EC, G3; $20 \%$ had serous or clear cell EC [7]. 75\% of patients had stage I, $25 \%$ had stage II disease. Patients with serous or clear cell stage I or II EC and positive peritoneal cytology were not admitted to the GOG-249 trial, and it was recommended that they should participate in the GOG-258 trial instead [7].

After a median follow-up time of 53 months, the recurrencefree 5-year survival rate of the group which received percutaneous radiotherapy was $76 \%(95 \% \mathrm{Cl}=0.70-0.81)$ and that of the brachytherapy/chemotherapy group was $76 \%(0.70-0.81)$. The hazard ratio was $0.92(90 \% \mathrm{Cl}=0.69-1.23)$. The 5 -year overall survival rate was $87 \%(95 \% \mathrm{Cl}=83-91 \%)$ for patients treated with percutaneous radiotherapy and $85 \%$ (95\% Cl: $81-90 \%)$ for the brachytherapy/chemotherapy group (HR: $1.04 ; 90 \% \mathrm{Cl}=0.71-$ 1.52). Rates of vaginal recurrence and distant metastasis were similar for both groups; pelvic and paraaortic recurrence was more common in the brachytherapy/chemotherapy group (9 vs. $4 \%)$ [7]. Acute toxicity was higher in the brachytherapy/chemotherapy group, while late toxicity was similar for both groups.

\section{Interpretation}

Interpreting the study results is easier if we take a brief critical look at the sometimes comparable and sometimes different concepts underpinning the three studies. To start with, we would like to congratulate both study groups for treating almost 2000 patients under controlled conditions in these three studies and generating valuable knowledge. The GOG-249 trial treated patients with carcinomas limited to the uterus (FIGO I or II and normal cytology), while the GOG-258 trial only included patients with extrauterine involvement (including positive lavage cytology of type-2 tumors). Supported by corresponding studies, the detailed description of which would go beyond the scope of this opinion, both American trials attempted to answer logical questions. The GOG-249 trial addressed the question whether "a little" chemotherapy combined with vaginal brachytherapy is better than external pelvic radiotherapy combined with optional vaginal brachytherapy. The GOG-258 trial investigated whether the addition of radiotherapy to chemotherapy offers benefits to patients with ad- 
vanced disease. In contrast, the PORTEC-3 trial aimed to investigate whether the addition of chemotherapy to radiotherapy is associated with improved overall survival. In the absence of resilient data on improvements to overall survival rates, this turning around of the question is particularly important for radiotherapy. Moreover, the inclusion criteria of the PORTEC-3 trial were far broader as they permitted the inclusion of patients with stage IA G3 and LVSI EC to stage IIIC disease.

The repeat evaluation of the PORTEC-3 trial using somewhat more mature data now shows very clearly that the addition of chemotherapy to percutaneous radiotherapy results in a significant and, above all, clinically relevant improvement in overall survival, particularly of patients with stage III or serous EC, compared to radiotherapy alone [5]. This logically expected outcome was not yet apparent in the first publication of the PORTEC-3 trial [1], as the data were not yet mature.

The PORTEC-3 trial does not answer the question whether patients with high-risk EC who receive sufficient adjuvant chemotherapy even need radiotherapy. The American GOG-258 trial aimed to answer that question. In an unambiguously high-risk cohort ( $97 \%$ of patients had stage III disease), adequate chemotherapy ( $6 \times$ carboplatin/paclitaxel; no vaginal brachytherapy) was defined as the standard and compared with simultaneous radiochemotherapy (external beam radiotherapy of the pelvis \pm paraaortic field \pm vaginal brachytherapy $+2 \times$ cisplatin), followed by 4 cycles of carboplatin/paclitaxel [6]. The additional radiotherapy improved locoregional control; however, distant metastasis occurred more often than in the group receiving chemotherapy alone [6]. The potential reason for this could be the reduction of full chemotherapy cycles from 6 to 4 or a delay in starting combination chemotherapy. Additional radiotherapy certainly did not lead to an improvement in recurrence-free survival. To date, overall survival is the same for both groups. It remains to be seen whether the reduction of distant metastasis in the group given chemotherapy alone will result in improved survival rates.

Consequently, as recommended in the S3-guideline [3], chemotherapy with carboplatin/paclitaxel remains the basis for adjuvant therapy to treat stage III disease. The recommendation that chemotherapy be used when treating serous tumors should be made clear.

The recommendation in the S3-guideline that percutaneous radiotherapy "may" be used to treat stage III EC can be upheld, as radiotherapy improved locoregional control in the GOG-258 trial but did not affect either overall or recurrence-free survival.

It is worth noting that the recurrence-free 5-year survival rate of the subgroup of patients with stage III disease in the radiochemotherapy arm of the PORTEC-3 trial was $71 \%$, a significantly better rate than the $59 \%$ reported for patients in the radiochemotherapy arm (>97\% consisted of patients with stage-III EC) of the GOG-258 trial or $58 \%$, the rate for its chemotherapy arm. But possible differences in the composition of the patient populations also need to be taken into account: around $70 \%$ of patients in the GOG-258 trial had stage IIIC1/2 disease compared to only $27 \%$ with stage IIIC disease in the PORTEC-3 trial $[5,6]$.
If, therefore, a patient is treated with adjuvant chemotherapy in accordance the standard arm of the GOG-258 trial, additional brachytherapy may be considered to reduce the rate of vaginal recurrence. If a patient is treated according to the protocol of the experimental arm of the GOG-258 trial, it is important to discuss with the patient whether reducing pelvic and paraaortic recurrence by administering percutaneous radiotherapy justifies the potential increase in distant metastasis, particularly as pelvic and/or paraaortic recurrence can be treated by secondary irradiation with good outcomes if no percutaneous irradiation was previously carried out $[3,8]$. The ongoing ECLAT trial will show whether lymph node recurrence is as common after adequate (therapeutic) pelvic and paraaortic lymphadenectomy followed by $6 \times$ carboplatin/paclitaxel and brachytherapy as the rates reported in the GOG-258 trial, where the median number of resected lymph nodes was only 13 pelvic and 3 paraaortic lymph nodes [6].

The authors of the GOG-249 trial emphasize that the majority of the patients they investigated would have been cured by surgery alone without any additional adjuvant measures. That was why only 3 cycles of chemotherapy were administered [7]. The authors emphasized the importance of determining those patients in this "high/intermediate risk" group who really need adjuvant therapy. The S3-guideline provides clear recommendations about the differentiated administration of brachytherapy, percutaneous irradiation and chemotherapy [3].

The ongoing PORTEC-4a trial will use modern molecular prognostic factors to differentiate patients in the "high/intermediate risk group" (here: stage IA, G3 to II G1). Combined with retrospective analysis, this should help to identify those women who probably do not require any adjuvant therapy and those patients for whom brachytherapy is adequate as well as the few cases who need percutaneous radiotherapy and/or chemotherapy [9].

The recent full publication of the results of 3 large phase-III trials on the use of adjuvant chemotherapy and radiotherapy in endometrial cancer does not necessitate any acute changes to the S3-guideline. The reported study results are entirely compatible with the current recommendations made in the guideline. The new data place an even greater emphasis on the benefit of adjuvant chemotherapy, especially when treating serous EC and stage III EC, than the current guideline. A fundamental analysis of the guideline and other publications will be carried out by the guideline group at the beginning of 2020, and the group will also consider to what extent current recommendations may need to be modified.

\section{Conflict of Interest}

The authors declare that they have no conflict of interest. 


\section{References}

[1] de Boer SM, Powell ME, Mileshkin L et al. Adjuvant chemoradiotherapy versus radiotherapy alone for women with high-risk endometrial cancer (PORTEC-3): final results of an international, open-label, multicentre, randomised, phase 3 trial. Lancet Oncol 2018; 19: 295-309. doi:10.1016/S1470-2045(18)30079-2

[2] Deutsche Gesellschaft für Radioonkologie (DEGRO). Hoch-Risiko-Endometriumkarzinom: Adjuvante Strahlentherapie bleibt Therapiestandard. Online: https://www.degro.org/hoch-risiko-endometriumkarzinomadjuvante-strahlentherapie-bleibt-therapiestandard/; last access: 02.08.2019

[3] Kommission Uterus der Arbeitsgemeinschaft Onkologie (AGO). S3-Leitlinie Diagnostik, Therapie und Nachsorge der Patientinnen mit Endometriumkarzinom. Version 1.0 - April 2018 AWMF-Registernummer: 032/034-OL. Online: https://www.leitlinienprogramm-onkologie.de/ leitlinien/endometriumkarzinom/; last access: 30.05.2018

[4] Emons G, Tempfer C, Battista M] et al. Statement of the Uterus Committee of the Gynaecological Oncology Working Group (AGO) on the PORTEC-3 study. Geburtsh Frauenheilk 2018; 78: 923-926. doi:10.1055/a-0658-1918
[5] de Boer SM, Powell ME, Mileshkin L et al. Adjuvant chemoradiotherapy versus radiotherapy alone in women with high-risk endometrial cancer (PORTEC-3): patterns of recurrence and post-hoc survival analysis of a randomised phase 3 trial. Lancet Oncol 2019. doi:10.1016/S1470-2045 (19)30395-X

[6] Matei D, Filiaci V, Randall ME et al. Adjuvant Chemotherapy plus Radiation for Locally Advanced Endometrial Cancer. N Engl J Med 2019; 380: 2317-2326. doi:10.1056/NEJMoa1813181

[7] Randall ME, Filiaci V, McMeekin DS et al. Phase III Trial: Adjuvant Pelvic Radiation Therapy Versus Vaginal Brachytherapy Plus Paclitaxel/Carboplatin in High-Intermediate and High-Risk Early Stage Endometrial Cancer. J Clin Oncol 2019; 37: 1810-1818. doi:10.1200/JCO.18.01575

[8] Ho JC, Allen PK, Jhingran A et al. Management of nodal recurrences of endometrial cancer with IMRT. Gynecol Oncol 2015; 139: 40-46. doi:10.1016/j.ygyno.2015.07.096

[9] Emons G, Vordermark D. Adjuvant treatment for endometrial cancer. Curr Opin Oncol 2019; 31: 404-410. doi:10.1097/CCO.0000000000000 558 